\title{
Experimental Investigation and High Resolution Simulator of In-Situ Combustion Processes
}

\section{Quarterly Report}

\author{
Start date: August 2003 \\ End date: December 2003 \\ Margot Gerritsen \\ Anthony R. Kovscek \\ January 2004 \\ DE-FC26-03 NT15405
}

\author{
Department of Petroleum Engineering \\ Stanford University \\ Green Earth Sciences Building \\ 367 Panama Street \\ Stanford, CA 94305-2220
}




\section{Disclaimer:}

This report was prepared as an account of work sponsored by an agency of the United States Government. Neither the United States Government nor any agency thereof, nor any of their employees, makes any warranty, express or implied, or assumes any legal liability or responsibility for the accuracy, completeness, or usefulness of any information, apparatus, product, or process disclosed, or represents that its use would not infringe privately owned rights. Reference herein to any specific commercial product, process, or service by trade name, trademark, manufacturer, or otherwise does not necessarily constitute or imply its endorsement, recommendation, or favoring by the United States Government or any agency thereof. The views and opinions of authors expresses herein do no necessarily state or reflect those of the United States Government or any agency thereof.

\section{Abstract}

Accurate simulation of in-situ combustion processes is computationally very challenging because the spatial and temporal scales over which the combustion process takes place are very small. In this first quarterly report of our DoE funded research, we discuss the design of a new simulation tool based on an efficient Cartesian Adaptive Mesh Refinement technique that allows much higher grid densities to be used near typical fronts than current simulators. The formulation presented here for a first one-dimensional simulator will serve as the foundation for the development of a three-dimensional simulator that can handle realistic permeability heterogeneity. The development of the simulation tool will be supported by extensive laboratory experiments conducted to provide validation data, and to study effective variants of the combustion process. The preliminary investigation reported here shows how metallic salt additives can promote and sustain combustion by enhancing the oxidation and cracking of hydrocarbons. 


\title{
Table of Contents
}

\author{
List of graphical materials
}

1. Introduction

2. Executive Summary

2.1. Personnel

2.2. Important accomplishments

3. Experimental

4. Results and discussion

5. Conclusion

References

\section{List of graphical materials}

Figure 1. Temperature profiles for Cymric oil with additives in half tube (tube run I)

Figure 2. Temperature profiles for Cymric oil with additives in full tube (tube run II) 


\section{Introduction}

In-situ combustion, or air injection, is the process of injecting oxygen into oil reservoirs to oxidize the heaviest components of the crude oil and enhance oil recovery through the heat and pressure produced. The emphasis of this work is to study and model numerically in situ combustion processes. The ultimate objectives are to provide a working accurate, parallel in situ combustion numerical simulator and to better understand the in-situ combustion process when using metallic additives and/or solvents combined with in situ combustion. For this purpose, experimental, analytical and numerical studies are conducted.

This report presents results of the first quarter of the first year of this project. 


\section{Executive Summary}

\subsection{Personnel}

Current personnel include Prof. Margot Gerritsen (PI), Prof. Tony Kovscek (Co-PI), Dr. Louis Castanier (Technical manager), Dr. Jonas Nilsson (postdoctoral fellow), Mr. Rami Younis (PhD student) and Mr. Bingjian He (MSc student).

We were very lucky to attract Dr. Jonas Nilsson, an expert in numerical modeling, from the University of Uppsala, Sweden, as postdoc on this project. He has started work on our 3D adaptive pressure solver for strongly heterogeneous media. He is assisted by $\mathrm{PhD}$ student Rami Younis. As a result phase 3 of the project is a little behind the schedule. However, we have already started work and made progress on phase 7 . We are confident that the early start of phase 7 will lead to an improved solver in phase 3.

\subsection{Important accomplishments}

\subsubsection{Development of the one-dimensional simulator}

We have started the design of a one-dimensional in-situ combustion simulator to be used as a validation tool for our novel computational methods. This simulator will also be used to compare numerical results with experimental results obtained in our in-situ combustion lab.

The physical system modeled in the 1D simulator consists of a core tube saturated with connate water and given oil. Properties of the core are homogeneous and isotropic, and the system is initially at equilibrium. The lateral surface of the core is perfectly insulated. At one end of the tube, fixed rate heat conduction is induced while injecting a fixed rate of air. At ignition temperatures, heat transfer at the injection end is discontinued. The duration of the process is the time until the producing end of the tube acquires a combustion front temperature. Axisymmetric transfer is assumed throughout the process.

We model four phases (gas, oil, water, and solid hydrocarbon) and six chemical components (Light Oil (LO), Heavy Oil (HO), Inert Gases (IG), Oxygen (O), Water (W), and Coke-like hydrocarbon (C) ). Four possible chemical reactions governed by first order Arrhenius kinetics are assumed to occur. Two model Low Temperature Oxidation reactions for both oil components, one models cracking, and the fourth models High Temperature Oxidation of the solid hydrocarbon component.

Currently, discretization of the governing equations is by central differences in space, and backward differences in time, treating the variables implicitly. Physical properties are modeled by classical and empirical correlations, making the governing equations nonlinear. A linearization approach to solving the system of discretized equations is adopted where the Jacobian is estimated numerically, and the resulting linearized system is solved by an iterative method. We have started the design of higher order upwind (ENO-type) schemes that may address numerical dissipation issues. We have extensive experience with these higher order schemes through our work on simulation of gas injection processes. There, accurate resolution of the propagating fronts is paramount to reliable sweep predictions.

The Adaptive Mesh Refinement AMR strategy adopted for the 1D simulator is patch based. A grid hierarchy is constructed. The adapted grid consists of the union of these grids. At the lowest level of the hierarchy is the coarsest grid covering the entire domain. A commonly used refinement ratio between levels is 2 since this minimizes computational overhead. 
We have completed the literature study on possible multi-grid solvers, and have designed the framework for the multigrid solver for both homogeneous and heterogeneous media. Since in this task the model permeability is homogenous and since the grid topology is isotropic on each level, a Full Multigrid solver with classical red/black Gauss Seidel smoother will be implemented to solve the linear system. The convergence properties are not expected to be optimal however due to h-ellipticity of the equations and variation in the property coefficients. This development however will lead us to address these first issues in designing appropriate multigrid methods. Primary modification will be to the smoothers applied.

\subsubsection{Extension of the simulator to three dimensions}

We have started the extension to three dimensions by implementing a 3D Cartesian anisotropic cell based mesh refinement method. The computational grid is formed by recursively splitting flagged cells in two, where the splitting is applied in all coordinate directions independently subject to the constraint that blocks cannot have more than two neighbors on any boundary. The obvious advantage of the cell based method is its simplicity, wherever refinement is needed grid cells are refined. Another advantage is that the narrow frontal zones in the in-situ combustion processes can be locally refined, without the refinements spread out into the entire domain. This leads to a memory saving method in terms of number of grid cells with the potential to save computer time. The detection algorithm for the refinement is based on saturation gradients and an approximate threshold.

The 3D Cartesian adaptive code we use is derived from the code developed for incompressible Navier-Stokes flow by Ham [1]. This code is currently running on our system and we are extending the solver to deal with heterogeneous media.

\subsubsection{Experimental in-situ combustion}

We conducted experiments in a kinetic cell to understand the role that metallic additives play in the cracking, low temperature oxidation and pyrolysis reactions leading to fuel formation during in-situ combustion. The oils, porous medium and metallic additives used are given in the next section.

One control run was performed to set the baseline case for fuel without additives. The equipment performed as planned. Energy of activation of the fuel deposition and combustion reactions were measured and matched literature results

Nitrogen experiments to test fuel lay down will be performed at a later stage. Experiments substituting clays with fine-grained silica flour are being conducted the data will be analysed and results discussed next quarter.

\section{Experimental}

\section{Choice of oils and solid matrix}

A heavy oil from Venezuela (Hamaca) and a light oil from The Cymric field in California were selected for the first set of experiments. The solid matrix will be a synthetic core composed of 95\% Ottawa sand and 5\% Kaolinite clay. This mix mimic well non consolidated reservoirs possible as candidates for combustion.

Selection of metallic additives 
Based on previous work (Shallcross, (1989), Castanier and Brigham (1996)) we have selected iron nitrate and tin chloride as the first two additives to be tested. Several other water soluble metallic salts will be tested in the near future.

\section{Results and discussion}

This report covers the first quarter of our research grant. As is clear from section 2, the quarter was used primarily to design the basic computational algorithms, and to establish the methodology for our experimental work. We have made significant progress in these areas and reported on our investigations at the SPE Western Regional Meeting in Bakersfield, CA, in March of this year [1].

Numerical results are forthcoming and will be covered in future reports.

As far as the experimental components of our research, we here describe two representative tube runs designed to investigate the effect of metallic additives (iron nitrate). In the first, only the top half of the tube contains iron nitrate while the bottom half does not. The purpose of this run was to gauge if a slug of metallic salt could promote enhanced combustion throughout the entire length of tube. In the second run, the metallic additive (iron nitrate) is added to the whole tube in order to verify consistency with previous metallic additive tests performed by Holt [2].

Tube run I: partial addition of metallic additive

Nitrogen was injected at $3 \mathrm{slpm}$. At $400^{\circ} \mathrm{C}$ the injection was shifted to air at the same rate. Figure 1 shows the observed temperature profiles for various times during the combustion run as function of the distance from the tube top.

For a front position ranging from the top, down to $60 \mathrm{~cm}$, the temperature of the combustion front remains around $400-450^{\circ} \mathrm{C}$ for the first $370 \mathrm{~min}$. In this time period the $\mathrm{CO}_{2}$ concentration varied between 8-12\% and a large amount of Oxygen is consumed as a result of the healthy combustion taking place. The $\mathrm{CO}$ concentration varies between 3-5\%. At 370 minutes, the temperature peak is at $56 \mathrm{~cm}$ from the top. The next peak temperature measured is a mere $270^{\circ} \mathrm{C}$ and the peak temperature declines thereafter. In between these two temperature measurements the combustion front passes the metallic additive interface, which is at roughly $52 \mathrm{~cm}$ from the top. The Oxygen concentration increases sharply, indicating that the combustion process is loosing efficiency. At about 450 minutes, the Oxygen levels approach $20 \%$, and the run dies out. Visual inspection of the sand confirmed that combustion had stopped at the interface between the sand with iron nitrate and the sand without it.

It is clear from this experiment that the ferric nitrate additive enhances the combustion performance and in the case of Cymric light oil is, in fact, necessary to sustain combustion. This is in agreement with previous findings. Further, it does not appear seem the iron nitrate is transported ahead of the front.

\section{Tube run II: Full addition of metallic additive}

The test conditions are similar to the first run apart from the distribution of additive throughout the combustion tube. The combustion was stopped at about 6.5 hours after the front reached $90 \mathrm{cms}$ from the top of the tube. We always stop the experiments at this stage to avoid damage to the outlet system. The combustion was sustained all the way with good $\mathrm{CO} 2$ production, high temperatures and good oxygen consumption.

Figure 2 shows the observed temperature profile. The front temperature peaks at $500^{\circ} \mathrm{C}$ at the start of the experiment, as a result of the ignition process, and then is steady at $400^{\circ} \mathrm{C}$ for the 
remainder of the run. Oxygen concentration in the produced gas was around $8 \%$, but at times as low as $3 \%$. Ample Oxygen injection is a necessary, but not sufficient, condition, for effective combustion.

Post mortem visual analysis of the burned sand showed a clean sand down to the position where combustion was quenched.

\section{Conclusions}

It is too early in the numerical algorithm development to draw sound conclusions from our preliminary investigations. The methods we propose in [1] are currently being tested. We do however feel that we are on the right track, judging from the very positive responses we have received so far from our industrial sponsors and university colleagues. We are confident at this stage that the experimental equipment allows collection of sufficient data to verify the one dimensional numerical simulator.

On the experimental side, it is apparent that metallic additives improve combustion of light oil. Without additives, some light oils (such as Cymric) could not sustain combustion. We will focus in the future on understanding how the additives work during combustion. Our current work is on the interaction between additives and the porous packing material. Kinetics experiments will be run to examine the role of the additives during fuel deposition and high temperature reactions.

\section{References}

[1] 'Experimental Investigation and High Resolution Simulator of in-situ Combustion Processes; 1. Simulator Design and Improved Combustion with Metallic Additives', SPE International Thermal Operations and Heavy Oil Symposium and Western Regional Meeting, Bakersfield, California, U.S.A., 16-18 March 2004. SPE 86962.

[2] Holt R. J., "In Situ Combustion With Metallic Additives", SUPRI TR. 87. July 1992. Stanford University. 


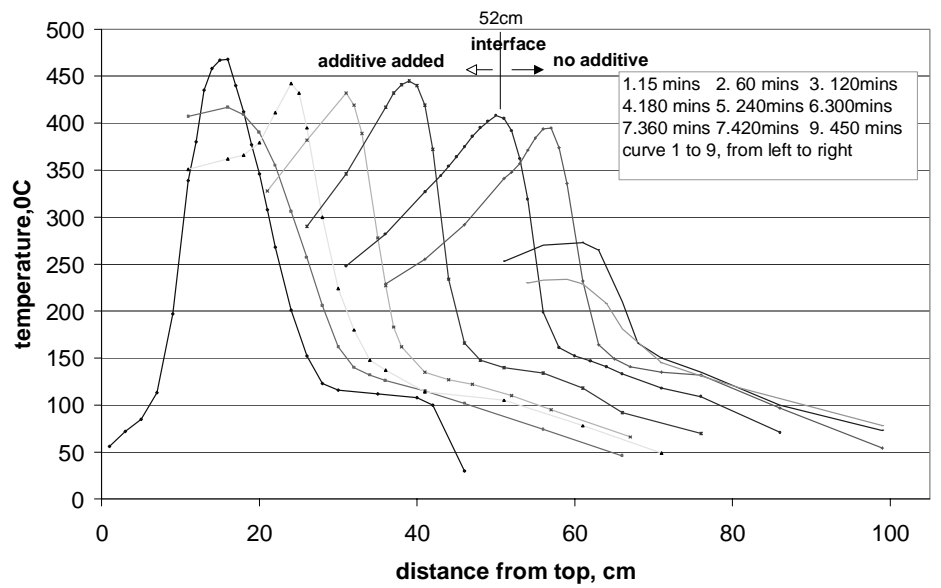

Figure 1. Temperature profiles for Cymric oil with additives in half tube (tube run I)

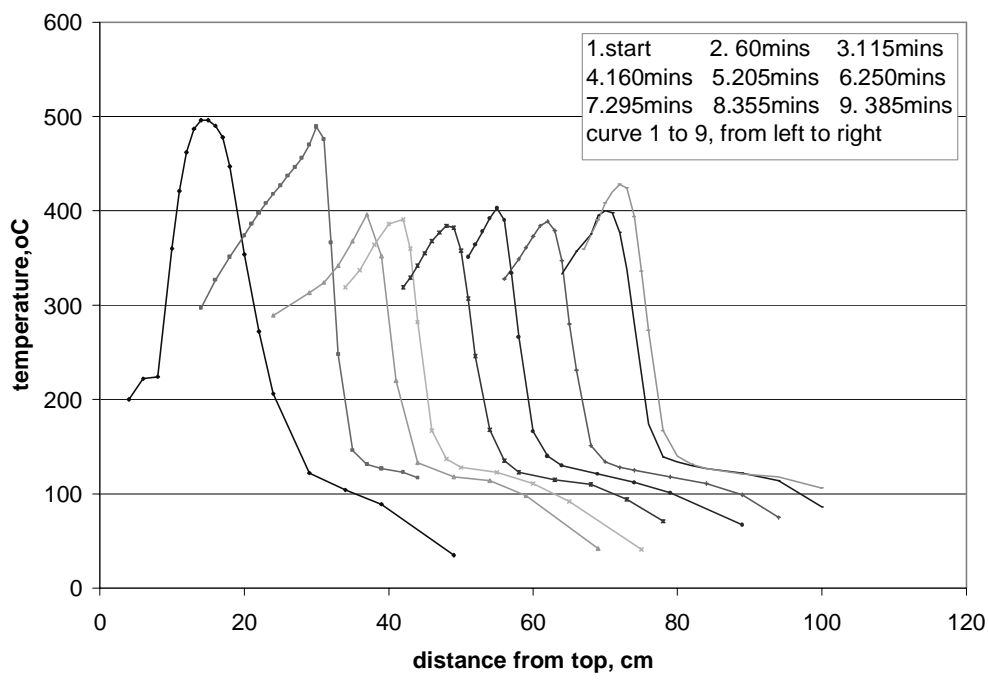

Figure 2. Temperature profiles for Cymric oil with additives in full tube (tube run II) 